\title{
Emphasis on Skin Physiology
}

The new ISI impact factors for 2008 are out, and we are very happy to announce that we have - again - improved. Our impact factor is now 2.388 , lifting the journal to number 10 in dermatology. Of course, this is due to our excellent authors, critical readers and the dedicated work of the reviewers and editorial team. We are hopeful that we can keep up this positive trend, knowing that we have the obligation to guarantee a sustainable improvement with hard work. This issue has a special emphasis on skin physiology, especially on aspects related to barrier function.

We are proud that one of the most influential professionals in modern dermatology, Albert Kligman, has contributed to this issue of the journal (Skin Pharmacol Physiol 2009;22: 178-189). Together with Gopinathan Menon, he reviews the current knowledge on the barrier functions of human skin. They evaluated the interdependent relation of skin barriers to environmental stressors. The authors highlight the fact that much information comes from studies on animal models, and they address specifically the differences between human and murine barrier repair. Furthermore, they focus on more recent findings, such as the role of antimicrobial and immune barriers, aquaporins and antioxidant barriers.

Man et al. (Skin Pharmacol Physiol 2009;22:190-199) report on variation of skin surface $\mathrm{pH}$, casual sebum content and stratum corneum hydration with age and gender in a large Chinese population. They studied 713 subjects divided into 5 age groups from birth up to over 70 years. The specific merit of this work is the assessment of skin physiology in a large number of Chinese volunteers in well-defined age groups in both genders with a multi-parametric non-invasive approach. Other ethnic groups should be characterized with the same rigor as in the present study.

Bellemère et al. (Skin Pharmacol Physiol 2009;22:200-209) report on the antiaging activity of retinol with a translational research approach leading from molecular to clinical studies. They could demonstrate that $0.1 \%$ retinol induced CRABP2 and $H B E G F$ gene expression and increased keratinocyte proliferation and epidermal thickness. Topical application of a retinol-containing product improved the aging signs of wrinkles under the eyes, fine lines and tone evenness.

Atrux-Tallau et al. (Skin Pharmacol Physiol 2009;22:210217) characterized the oxygen transport into and through porcine skin exposed to oxygen-saturated water. The authors show that exogenous delivery of oxygen to skin tissue was more effective than endogenous delivery through intact and stripped skin. They conclude that oxygen carrier formulations might improve the oxygen status in the skin.

Song et al. (Skin Pharmacol Physiol 2009;22:218-224) studied cutaneous resonance running time (CRRT) in cured leprosy subjects. The group had made previous observations with this technique and was now able to show abnormal CRRT in cured leprosy. Furthermore, different leprosy subtypes with distinctive CRRT could be characterized. The authors point out that the extent of reduction of CRRTs correlates with the severity of immune alteration. Thus, CRRT might be useful in quantifying the extent of residual abnormalities in cured leprosy and perhaps could also be used to evaluate treatment efficacy.

Watkinson et al. (Skin Pharmacol Physiol 2009;22:225230) studied the influence of propylene glycol (PG) on ibuprofen permeation. This publication is the group's second on optimization of solvent concentration for topical drug delivery (see also Skin Pharmacol Physiol 2009;22:15-21). They could show that the influence of PG in PG:water systems is primarily due to the solubility and partitioning behavior of ibuprofen.

Coming back from summer and from very fruitful meetings of the ISP in Boston as well as the Gordon-ResearchConference on barrier function of mammalian skin (in a later issue we will report in more detail), we would like to wish you well for the last part of the year and, especially, for the planning phase of 2010. We are looking forward to receiving your manuscripts and critical comments on the current issue of the journal.

Joachim Fluhr, President of the ISP Jürgen Lademann, Editor

\begin{tabular}{ll}
\hline KARGER & @ 2009 S. Karger AG, Basel \\
Fax $+41660-5527 / 09 / 0224-0177 \$ 26.00 / 0$ \\
$\begin{array}{l}\text { E-Mail karger@karger.ch } \\
\text { www.karger.com }\end{array}$ & $\begin{array}{l}\text { Accessible online at: } \\
\text { www.karger.com/spp }\end{array}$
\end{tabular}

